\title{
Factors Associated with Birth Preparedness and Complication Readiness Among Pregnant Women in Bench Maji Zone, Southwest Ethiopia: A Community-Based Cross-Sectional Study
}

\author{
Tesfaye Abera Gudeta ${ }^{*}$, Tilahun Mekonnon Regassa ${ }^{1}$
}

\author{
OPEN ACCESS \\ Citation: Tesfaye Abera Gudeta, Tilahun \\ Mekonnon Regassa. Factors Associated \\ With Birth Preparedness and \\ Complication Readiness Among Pregnant \\ Women in Bench Maji Zone, Southwest \\ Ethiopia: A Community-Based Cross- \\ Sectional Study. Ethiop J Health \\ Sci.2019;29 (5):567.doi:http://dx.doi.org/ \\ 10.4314/ejhs.v29i5.6 \\ Received: April 9, 2019 \\ Accepted: June 5, 2019 \\ Published: September 1, 2019 \\ Copyright: (C) 2019 Tesfaye Abera \\ Gudeta, et al. This is an open access \\ article distributed under the terms of the \\ Creative Commons Attribution License, \\ which permits unrestricted use, \\ distribution, and reproduction in any \\ medium, provided the original author and \\ source are credited. \\ Funding: Mizan-Tepi University \\ Competing Interests: The authors \\ declare that this manuscript was approved \\ by all authors in its form and that no \\ competing interest exists. \\ Affiliation and Correspondence: \\ ${ }^{1}$ Department of Nursing, College of \\ Health Sciences, Mizan-Tepi \\ University, Ethiopia \\ *Email: tesfeabera2013@gmail.com
}

\begin{abstract}
ABSRACT
BACKGROUND: Birth preparedness and complication readiness is the process of preparing for normal birth and anticipating the actions needed in case of an emergency. About 300 million women in the developing world affected by short-term or long-term illness, even death brought by pregnancy and childbirth. This is because insufficiency birth and emergency preparedness. The objective of this study was to assess birth preparedness and complication readiness, and its associated factors among pregnant women in Bench Maji Zone.

METHODS AND MATERIALS: A community based crosssectional study was conducted 'on 605 participants. Multi-stage sampling was used to select woredas and kebeles by simple random sampling technique. The study subjects were selected by systematic sampling technique. Multivariable logistic regression analysis was used to control confounds. Odds ratio (OR) with 95\% confidence interval was used to examine associations between dependent and independent variables. P-value of less than 0.05 was considered significant.
\end{abstract}

RESULT: This study identified that the knowledge and practice of respondents about birth preparedness and complication readiness were $285(48.4 \%)$ and $249(42.3 \%)$ respectively. Place of residence (AOR 2.0; 95\%CI: 1.2- 3.2), occupational status of mother (AOR3.2; 95\%CI: 1.2- 8.1), knowledge of BP/CR (AOR 12.6; 95\%CI: 7.5-21.4) and knowledge of danger sign during pregnancy (AOR 1.9; 95\%CI: 1.1-3.3) were found to have statistically significant association.

CONCLUSION: The status of birth preparedness and complication readiness was low. Place of residence, occupation, having knowledge about birth preparedness and complication readiness, and having knowledge about danger signs during pregnancy were the factors associated with birth preparedness and complication readiness.

KEYWORDS: Birth preparedness, complication readiness, pregnancy, women, Ethiopia 


\section{INTRODUCTION}

Birth Preparedness and Complication Readiness $(\mathrm{BP} / \mathrm{CR})$ is considered as preparation for normal birth and readiness to take emergency actions when needed which is important for safety and healthiness of mothers and newborns during pregnancy, labor and child birth, and post-partum. Any pregnant woman is at risk to develop pregnancy complications which are not predictable, and that can cause morbidity or mortality of both mothers and her newborns $(1,2)$.

The policies support that all pregnant women must get maternal and neonatal health care. The health care system also guarantees that all health care providers who give service for pregnant women and their families must have the abilities to support woman in birth preparedness and complication readiness (3).

More than $40 \%$ of pregnant women may develop acute obstetric complication, globally. The WHO estimates that 300 million women in low income countries suffer from short-term or long-term complications related to pregnancy and childbirth (3). In $2008,52 \%$ of maternal deaths out of 342,900 occurred in sub-Saharan Africa. Inadequacy or lack of birth preparedness and complication readiness is among the main reasons of maternal deaths, which is an important component of globally accepted programs of safe maternal health. Birth preparedness and emergency readiness helps the women to be attended by professionals when labour begins and decreases delays that occur when mothers develop obstetric complications (4).

Apart from medical causes, there are many interrelated socio-cultural factors which delay careseeking and contribute to maternal deaths, because of non-preparation. Thus BP and CR is one of the interventions that address these delays by encouraging pregnant women, their families and communities to effectively plan for births and deal with emergencies, if they occur(5).

The approach of BP/CR has been encouraged in many African countries at the level of mother, family and community to prvent home delivery and potential complications. This approach includes identifying a health facility for emergency, trained birth attendant for delivery, attainment of sterile/clean materials (blade, soap, cord ties, clean linen), saving money for delivery, arranging transportation to a facility, and planning for referral if needed and also ensure women to be informed of danger signs .

However most of pregnant mothers and their families are not aware about how to recognize the danger signs of complications. The unprepared family will waste time in getting organized, getting money, recognizing the complications, reaching the appropriate referral facility and finding transport $(2,6,7)$.

Generally, BP/CR significantly reduces maternal mortality and morbidity. Ethiopia is among the low income countries, in which maternal mortality ratio is 412 deaths per 100,000 live births (8), it is important to have up-to-date information about birth preparedness and complication readiness and its associated factors for policy makers and program implications at different levels. However, studies on this issue are not sufficient in Ethiopia, especially in the study area (Bench Maji Zone), this study was planned to fill this gap.

\section{METHODS}

Study area and period: This study was conducted in Bench Maji Zone from December 01 -30/2016. Bench Maji is one of the zones found in the Ethiopian Southern Nations, Nationalities and Peoples Region (SNNPR) , $565 \mathrm{~km}$ away from the Addis Abeba. The zone consists of one administration town and ten woredas. According to the Zonal Health Department report of 2015, the zone had estimated population of 829,493; of them 181,974 were women of childbearing age, and there were about 28,700 expected pregnant women (9).

Study design: A community-based cross-sectional study design with quantitative methods of data collection was used.

Source and study population: All pregnant women in Bench Maji zone were source of population. All sampled pregnant women in the selected woredas were study population.

Inclusion and exclusion criteria: All pregnant women in selected kebeles with gestational age of $\geq$ 16 weeks and those who lived in the kebeles for six or more months were included in the study. Pregnant women who were critically ill and mentally incapable to communicate were excluded from the study.

Sample size determination and sampling technique: Sample size (605) was determined using single population proportion formula with the

DOI: http://dx.doi.org/10.4314/ejhs.v29i5.6 
following assumptions: $d=$ margin of error of $5 \%$ with $95 \%$ confidence interval, $\mathrm{p}=$ proportion of expected prevalence of $\mathrm{BP} / \mathrm{CR}$ being $23.3 \%$.The multistage sampling was used to select woredas and kebeles. The five woredas were selected by simple random sampling (SRS) technique. Based on source population, the sample size of each woreda was proportionally allocated. From the selected woredas again, the kebeles were selected by lottery method. Then, the sample size was proportionally allocated to each kebeles. Then, systematic sampling technique was used to select eligible pregnant women. The list of pregnant women was taken from health posts of each kebele.

\section{Operational definitions}

Knowledgeable on BP and CR- In this study a woman was taken as knowledgeable if she answered at least four of knowledge questions about birth preparedness and complication readiness.

Knowledgeable on key danger signs during pregnancy-If she was able to spontaneously answere at least three among the key danger signs of pregnancy (vaginal bleeding, swollen hands/face, high fever, blurred vision, severe abdominal pain and sever head ache).

Knowledgeable on key danger signs of Labor/child birth- If she could mention at least three key danger signs for labor/child birth (sever vaginal bleeding, prolonged labor, convulsions, and retained placenta).

Knowledgeable on key danger signs of postpartum- A woman was considered knowledgeable about danger signs of postpartum if she could mention at least two of the three main danger signs for postpartum (severe vaginal bleeding, foul-smelling vaginal discharge and high fever) spontaneously.

Birth preparedness and complication ready- A woman was considered as prepared for birth preparedness and its complication readiness if she identified four and more components from birth preparedness and complication readiness $(10,11)$.

Data collection technique and tools: The data was collected using pre-tested structured questionnaire of Amharic version.The questionnaire was adapted from the survey tools developed by JHPIEGO maternal neonatal health program (12). Because of the adaptation of the tool, content validity was checked by experts. The questions and statements were grouped and arranged according to the particular objectives that they could address.
Fifteen data collectors who were nurse and midwives working at a nearby health facility were recruited purposively from their respective woredas, and four supervisors who are BSc in health were recruited. Data was collected by trained data collectors through face-to-face interview using pre-tested structured questionnaire.

Quality control measures,data processing and analysis: Validated pre-tested questionnaires were used to ensure quality of data. Pre-test was done on $5 \%$ of the total study subjects, prior to the actual data collection. Training was given for data collectors intensively for two days. The traing focused on the relevance of the study, objective of the stud, instrument, data collection procedure, how to ensure confidentiality and interview technique.

Close supervision was done to ensure adherence to correct data collection procedures, every day supervisors reviewed the filled questionnaires at the end of data collection for completeness. In addition, every morning, the supervisors and data collectors conducted morning session to solve if there was any problems encountered. Moreover, before the beginning of analysis, data was carefully entered and cleaned.

EPI data Statistical software version 3.1 was used for data entry, and Statistical Package for Social Sciences (SPSS) software version 21.0 was used for data analysis. After organizing and cleaning the data, frequencies and percentages were calculated for all variables that were related to the objectives of the study.

Binary logistic regression analysis was used to identify predictors of BP and CR. Variables with Pvalue of less than 0.25 in binary logistic regression analysis were entered into the multivariable logistic regression analysis to control confounds.

Odds ratio with $95 \%$ confidence interval was used to examine associations between dependent and independent variables. P-value of less than 0.05 were considered significant. Finally, the results were presented using tables and narrative form.

Ethical considerations: Ethical clearance was taken from MizanTepi University Research Review Committee. Permission letter from respective authorities and written consent from respondents were obtained before the data collection. To get full co-operation, respondents were reassured about the confidentiality of their responses. They were also ensured about their voluntarily participation and right to take part or terminate at any time they

DOI: http://dx.doi.org/10.4314/ejhs.v29i5.6 
wanted. Since the subjects of the study could raise ethical issues, cares were taken in the design of the questionnaire.

\section{RESULTS}

Socio-demographic characteristics of the study participants: Among the total study participants, $258(43.8 \%)$ were age between 25-29 years. Regarding their religion, 261(44.35\%) were protestant. Around 576(97.8\%) were married by their marital status. More than half, 358(60.8\%), of the study participants were rural residents.

Regarding educational level, 236(40.1\%) of the respondents were not able to read and write. The majority, $400(67.9 \%)$ of the respondents were housewives and more than half $371(63 \%)$ respondents had less than four family size (Table 1).

Table 1: Distribution of the study participants by their socio- demographic characteristics at Bench Maji Zone, Southwest, Ethiopia, 2016

\begin{tabular}{|c|c|c|c|}
\hline Variable & category & Frequency $(\mathrm{n}=589)$ & Percent \\
\hline \multirow[t]{5}{*}{ Age } & $15-19$ & 15 & 2.5 \\
\hline & $20-24$ & 129 & 21.9 \\
\hline & $25-29$ & 258 & 43.8 \\
\hline & $30-34$ & 129 & 21.9 \\
\hline & $>=35$ & 58 & 9.8 \\
\hline \multirow[t]{3}{*}{ Marital status } & single & 11 & 1.9 \\
\hline & Married & 576 & 97.8 \\
\hline & Divorced & 2 & 0.3 \\
\hline \multirow[t]{2}{*}{ Age at first marriage $(n=580)$} & $<=17$ & 92 & 15.9 \\
\hline & $>=18$ & 488 & 84.1 \\
\hline \multirow[t]{2}{*}{ Residence } & Urban & 231 & 39.2 \\
\hline & Rural & 358 & 60.8 \\
\hline \multirow[t]{3}{*}{ Religion } & Orthodox & 277 & 47.0 \\
\hline & Muslim & 51 & 8.7 \\
\hline & Protestant & 261 & 44.3 \\
\hline \multirow[t]{5}{*}{ Educational status of mothers } & Illiterate & 236 & 40.1 \\
\hline & Can read and write & 176 & 29.9 \\
\hline & Primary Cycle(1-8) & 71 & 12.1 \\
\hline & Secondary and preparatory & 44 & 7.5 \\
\hline & Diploma and above & 62 & 10.5 \\
\hline \multirow[t]{6}{*}{ Occupation of mother } & Governmental employer & 76 & 12.9 \\
\hline & NGO & 14 & 2.4 \\
\hline & Housewife & 400 & 67.9 \\
\hline & Laborer & 5 & 0.8 \\
\hline & Merchant & 84 & 14.3 \\
\hline & Other & 10 & 1.7 \\
\hline \multirow[t]{5}{*}{ Educational status of husbands $(\mathrm{n}=577)$} & Illiterate & 146 & 25.3 \\
\hline & Can read and write & 209 & 36.2 \\
\hline & Primary cycles(1-8) & 61 & 10.6 \\
\hline & Secondary Cycle & 81 & 14.0 \\
\hline & Diploma and above & 80 & 13.9 \\
\hline \multirow[t]{6}{*}{ Occupation of husbands ( $\mathrm{n}=577$ ) } & Governmental Employer & 92 & 15.9 \\
\hline & NGO & 23 & 4.0 \\
\hline & Farmer & 367 & 63.6 \\
\hline & Merchant & 66 & 11.4 \\
\hline & Laborer & 26 & 4.5 \\
\hline & Other & 3 & 0.5 \\
\hline \multirow[t]{3}{*}{ Family size category } & $<=4$ & 371 & 63.0 \\
\hline & $5-6$ & 136 & 23.1 \\
\hline & $>=7$ & 82 & 13.9 \\
\hline
\end{tabular}

DOI: http://dx.doi.org/10.4314/ejhs.v29i5.6 
Variables related to obstetrics: Regarding the gravida of the mother, more than half $346(58.7 \%)$ were $2-4$, and the majority $451(76.6 \%)$ of them were multiparous. Concerning the status of current pregnancy, 526(89.3\%) were wanted, and almost half $308(52.3 \%)$ of them were on the third trimester during interview. Among the respondents, 22(3.7\%) had history of stillbirth, and $36(6.1 \%)$ had history of abortion (Table 2 ).

Table 2: Obstetrics history of the pregnant women at Bench Maji Zone, Southwest, Ethiopia, 2016

\begin{tabular}{llcc}
\hline Variable & Category & $\begin{array}{c}\text { Frequency } \\
(\mathrm{n}=589)\end{array}$ & Percent \\
\hline Gravida & 1 & 138 & 23.4 \\
& $2-4$ & 346 & 58.7 \\
\multirow{4}{*}{ Parity } & $>4$ & 105 & 17.8 \\
& Non parours & 138 & 23.4 \\
Trimester during interview & Parous & 451 & 76.6 \\
& $2^{\text {nd }}$ & 281 & 47.7 \\
History of still birth & $3^{\text {rd }}$ & 308 & 52.3 \\
\multirow{2}{*}{ History abortion } & Yes & 22 & 3.7 \\
& No & 567 & 96.3 \\
Status of current pregnancy & Yes & 36 & 6.1 \\
& NO & 553 & 93.9 \\
& Wanted & 526 & 89.3 \\
\hline
\end{tabular}

Knowledge of respondents about birth preparedness and its complication readiness: In primary source of information about birth this study, the majority, 572 (97.1) of the preparedness and complication readiness, respondents had information about birth 494(85.8\%) were health extension workers preparedness and complication readiness. The followed by health professionals $278(48.3 \%)$.

Table 3: Knowledge of respondents about birth preparedness and its complication readiness among pregnant women in Bench Maji zone, Southweast, Ethiopia, 2016

\begin{tabular}{llcc}
\hline BP/CR component & Response & Frequency(n=589) & Percent \\
\hline Identification of place of delivery & Yes & 502 & 85.2 \\
& No & 87 & 14.8 \\
Identification of skilled birth attendants & Yes & 403 & 68.4 \\
Saving money & No & 186 & 31.6 \\
& Yes & 273 & 46.3 \\
Prepare essential items for child birth & No & 316 & 53.7 \\
& Yes & 346 & 58.7 \\
Recognition of danger signs ( pregnancy ,Labour \&Post natal) $)$ & Ye & 243 & 41.3 \\
& No & 403 & 68.4 \\
Identification of mode of transport & Yes & 186 & 31.6 \\
& No & 106 & 18.0 \\
Decision maker and support person & Yes & 483 & 82.0 \\
& No & 84 & 14.3 \\
Arranging blood donor & Yes & 505 & 85.7 \\
& No & 44 & 7.5 \\
Overall knowledge & Knowledgeable & 545 & 92.5 \\
& Not & 285 & 48.4 \\
& knowledgeable & 304 & 51.6 \\
\hline
\end{tabular}

DOI: http://dx.doi.org/10.4314/ejhs.v29i5.6 
Regarding the knowledge of respondents about birth preparedness and its complication readiness, 502(85.2\%), 403(68.4\%), 273(46.3) and 44(7.5\%) knew identification of place of delivery, identification of skilled birth attendant, saving money and arranging blood donor respectively. From the total score of knowledge, 285(48.4\%) of the respondents were identified as knowledgeable about BP/CR (Table 3).

Knowledge of key danger signs during pregnancy, labour and child birth, and postpartum: Severe vaginal bleeding, swollen hands/face, blurred vision, high fever, severe abdominal pain and severe headache were the six main danger signs during pregnancy that were spontaneously mentioned by $529(89.8 \%)$, 285(4948.4\%), 238 (40.4\%), 260 (44.1\%), $205(34.8 \%)$ and $270(45.8 \%)$ respectively. However, all the six key danger signs during pregnancy were spontaneously mentioned only by $86(14.6 \%)$ respondents.
The four key danger signs during labor and delivery (severe vaginal bleeding, prolonged labor $(>12 \mathrm{hrs})$, convulsions and retained placenta) were spontaneously mentioned by $486(82.5 \%), 206$ $(35.0 \%), \quad 177(30.1 \%)$ and 265(45.0\%) respectively. Few of the respondents, $47(8.0 \%)$, were able to answere all the four key danger signs during labour and delivery spontaneously. The three key danger signs during postnatal period (severe vaginal bleeding, foul smelling vaginal discharge and high fever) were spontaneously mentioned by 539(91.5\%), 189(32.1) and $227(38.5 \%)$ respectively. However 132(22.4\%) women were able to mention all the three crucial danger signs during post-partum spontaneous.

The overall knowledge on danger signs, $329(55.9 \%), 145(24.6 \%)$, and $257(43.6 \%)$ of the respondents were found to be knowledgeable on obstetric danger signs during pregnancy, labor and childbirth and postpartum respectively (Table 4).

Table 4: Knowledge of respondents about key danger signs during pregnancy, labour and child birth and post-partum,Bench Maji zone,Southwest, Ethiopia, 2016.

\begin{tabular}{llcc}
\hline Variables of danger sign & & Frequency & Percent \\
\hline Knowledge of key danger sign during & Knowledgeable & 329 & $\mathbf{5 5 . 9}$ \\
pregnancy & Not knowledgeable & 260 & 44.1 \\
Knowledge of key danger sign during & Knowledgeable & 145 & $\mathbf{2 4 . 6}$ \\
labour and child birth & Not knowledgeable & 444 & 75.4 \\
Knowledge of key danger sign during & Knowledgeable & 257 & $\mathbf{4 3 . 6}$ \\
post-partum & Not knowledgeable & 332 & 56.4 \\
\hline
\end{tabular}

Antenatal care experience and history of previous delivery: Almost all, 575(98.0\%) of the respondents attended antenatal care (ANC) at least once in their current pregnancy. Among those pregnant women who attended ANC, the majority $498(86.6 \%)$ had $1-3$ visits while $77(13.4 \%)$ had more than three visits.

Among pregnant women who attended ANC, most of them 567(98.6\%) received advice from care providers on the components of birth preparedness and complication readiness. Accordingly,502(87.8\%) of them adviced where to deliver, $406(71.0 \%)$ identifying skilled birth attendants, 294(51.4\%) on saving money for delivery and emergency, $133(23.3 \%)$ on mode of transportation, $94(16.4 \%)$ on the identifying decision maker and support person, 373(65.2\%) on danger signs, $321(56.1 \%)$ on the preparation of items for delivery and $37(6.5 \%)$ on arranging blood donor in case of emergency.

Among the study participants, 452(76.7\%) gave birth previously. Among those who had delivery in the past, more than have, $289(63.8 \%)$, of the respondents gave recent birth in health facility, and 164(36.2\%) gave recent birth at home. Among the respondents who had delivery in the past, the recent birth were attended by $286(63.3 \%)$ skilled birth attendants, 33(7.3\%) trained traditional birth attendants, 33(7.3\%) untrained traditional birth attendants and 100 (22.1\%) family member/neighbor/self. Among those who had at least one delivery in the past, during their recent pregnancy, 391(86.5\%) had at least one ANC visit, and more than half of the 
respondents, $250(63.6 \%)$, had $1-3$ visits and $143(36.4 \%)$ had more than three visits.

Practices of birth preparedness and complication readiness: Majority 563(95.6\%) of the respondents reported that they made at least one arrangement for birth and ready for complication. Among the eight elements of BP and CR practice, $493(83.7 \%)$ of respondents were identified place of delivery, 397(67.4\%) planned to be attended by skilled attendant for their current pregnancy, 266(45.2\%) were started saving money and 335(56.9) were started preparation of essential items for child birth. Birth preparedness and complication readiness score was computed from components of $\mathrm{BP} / \mathrm{CR}$. Then categorized as well prepared if the woman scored four or more out of the eight BP/CR elements. Accordingly, out of the total, $249(42.3 \%)$ of the pregnant women in this study were considered as well prepared for birth and complications (Table 5).

Table 5: Practice of respondents about birth preparedness and its complication readiness among pregnant women in Bench Maji zone, Southweast, Ethiopia, 2016.

\begin{tabular}{|c|c|c|c|}
\hline Practice BP/CR & Response & $\begin{array}{c}\text { Frequency } \\
(n=589)\end{array}$ & Percent \\
\hline \multirow[t]{2}{*}{ Identification of place of delivery } & Yes & 493 & 83.7 \\
\hline & No & 96 & 16.3 \\
\hline \multirow[t]{2}{*}{ Identification of skilled birth attendants } & Yes & 397 & 67.4 \\
\hline & No & 192 & 32.6 \\
\hline \multirow[t]{2}{*}{ Saving money } & Yes & 266 & 45.2 \\
\hline & No & 323 & 54.8 \\
\hline \multirow[t]{2}{*}{ Prepare essential items for child birth } & Yes & 335 & 56.9 \\
\hline & No & 254 & 43.1 \\
\hline Recognition of danger signs ( pregnancy ,labour & Yes & 335 & 56.9 \\
\hline$\&$ Post natal) & No & 254 & 43.1 \\
\hline \multirow[t]{2}{*}{ Identification of mode of transport } & Yes & 99 & 16.8 \\
\hline & No & 490 & 83.2 \\
\hline \multirow[t]{2}{*}{ Decision maker and support person } & Yes & 79 & 13.4 \\
\hline & No & 510 & 86.6 \\
\hline \multirow[t]{2}{*}{ Arranging blood donor } & Yes & 33 & 5.6 \\
\hline & No & 556 & 94.4 \\
\hline \multirow{2}{*}{ Over all practice of $\mathrm{BP} / \mathrm{CR}$} & Practiced & 249 & 42.3 \\
\hline & Not practiced & 340 & 57.7 \\
\hline
\end{tabular}

Factors affecting birth preparedness and complication readiness: The binary logistic regression analysis was done to see the association between the dependent and the independent variables and to identify the candidate variables for multivariable logistic regression. Among the candidate variables for multivariable logistic regression, which were analyzed with bivariate logistic regression; Residence, Educational status of mother, Occupational status of mother, Family size, Gravida, Parity,Trimester during interview, Having Information, Knowledge of $\mathrm{BP} / \mathrm{CR}$, Danger sign during Pregnancy, During Labour and Delivery, During Post Natal and Previous delivery.

In multivariable logistic regression analysis, factors associated with $\mathrm{BP} / \mathrm{CR}$ were identified.
Accordingly, Residence, Occupational status of mother, Knowledge of BP/CR and Knowledge of danger sign During Pregnancy were statistically associated with $\mathrm{BP}$ and $\mathrm{CR}$ practice. Women from urban residence $(\mathrm{OR}=2.0 ; 95 \% \mathrm{CI}$ : 1.2- 3.2) were more likely to be prepared for birth and its complications. Women who were employed (Gov't, NGO) (OR=3.2; 95\%CI: 1.2- 8.1) were more likely to be prepared as compared to women who were housewives.

Women who knew at least four components of $\mathrm{BP} / \mathrm{CR}(\mathrm{OR}=12.6$; 95\%CI: 7.5-21.4) were more likely prepared for $\mathrm{BP} / \mathrm{CR}$ as compared to the women who were not knowledgeable. Similarly, women who were knowledgeable about key danger signs during pregnancy $(\mathrm{OR}=1.9 ; 95 \% \mathrm{CI}$ :

DOI: http://dx.doi.org/10.4314/ejhs.v29i5.6 
1.1-3.3) were more likely prepared as compared to those not knowledgeable (Table 6).

Table 6: Multivariable logistic regression analysis of birth preparedness and complication readiness and its associated factors among pregnant women at Bench Maji Zone, Southwestern Ethiopia, 2016.

\begin{tabular}{|c|c|c|c|}
\hline Variables & Category & COR (95\% CI) & AOR (95\%CI) \\
\hline \multirow[t]{2}{*}{ Marital Status } & In Marital Union & $2.5(0.7-9.1)$ & $0.7(0.2-3.5)$ \\
\hline & Not in Marital Union & 1 & 1 \\
\hline \multirow[t]{2}{*}{ Residence } & Urban & $3.0(2.1-4.2)^{*}$ & $2.0(1.2-3.2) *$ \\
\hline & Rural & 1 & 1 \\
\hline \multirow{6}{*}{$\begin{array}{l}\text { Educational } \\
\text { mother }\end{array}$} & Illiterate/ Can't read and write & 1 & 1 \\
\hline & Can read and write & $2.1(1.4-3.2)^{*}$ & $0.8(0.4-1.4)$ \\
\hline & Primary cycles(1-8) & $1.8(1.1-3.1)^{*}$ & $0.6(0.3-1.4)$ \\
\hline & Secondary and preparatory & $3.5(1.8-6.6) *$ & $0.4(0.2-1.1)$ \\
\hline & Diploma and above & 2.2(1.3-3.9)* & $0.1(0.04-1.2)$ \\
\hline & House Wife & 1 & 1 \\
\hline \multirow{3}{*}{$\begin{array}{l}\text { Occupational status of } \\
\text { mother }\end{array}$} & Employed(Gov’t, NGO) & $1.8(1.2-2.9) *$ & $3.2(1.2-8.1)^{*}$ \\
\hline & Merchant & $1.8(1.2-3.0)^{*}$ & $1.4(0.7-2.7)$ \\
\hline & Other++ & $2.5(0.9-7.2)$ & $2.1(0.5-9.0)$ \\
\hline \multirow[t]{3}{*}{ Family size } & $<=4$ & 1 & 1 \\
\hline & $5-6$ & $0.8(0.6-1.2)$ & $0.9(0.5-1.7)$ \\
\hline & $>=7$ & $0.5(0.3-0.8) *$ & $1.2(0.5-3.4)$ \\
\hline \multirow[t]{3}{*}{ Gravida } & 1 & 1 & 1 \\
\hline & $2-4$ & $0.7(0.9-\quad 1.1)$ & $0.4(0.02-8.4)$ \\
\hline & $>4$ & $0.5(0.3-0.9) *$ & $0.4(0.02-8.7)$ \\
\hline \multirow[t]{2}{*}{ Parity } & Primparous & 1 & 1 \\
\hline & Multiparous & $0.7(0.5-1.0)$ & $5.5(0.2-147.2)$ \\
\hline \multirow{2}{*}{$\begin{array}{l}\text { Trimester during } \\
\text { interview }\end{array}$} & 2nd & 1 & 1 \\
\hline & $3 \mathrm{rd}$ & $1.2(0.9-\quad 1.7)$ & $1.0(0.6-1.5)$ \\
\hline \multirow[t]{2}{*}{ Having Information } & Yes & $3.5(1.0-12.4) *$ & $1.4(0.3-6.4)$ \\
\hline & No & 1 & 1 \\
\hline \multirow[t]{2}{*}{ Knowledge of BP/CR } & Knowledgeable & $17.3(11.4-26.4 *$ & $12.6(7.5-21.4) *$ \\
\hline & Not Knowledgeable & 1 & 1 \\
\hline \multicolumn{4}{|c|}{ Knowledge of Danger Sign } \\
\hline \multirow[t]{2}{*}{ During Pregnancy } & Knowledgeable & $5.8(4.0-$ & $1.9(1.1-3.3)^{*}$ \\
\hline & Not Knowledgeable & 1 & 1 \\
\hline \multirow{2}{*}{$\begin{array}{l}\text { During Labour and } \\
\text { Delivery }\end{array}$} & Knowledgeable & 4.6(3.1- 6.9$)^{*}$ & $1.4(0.8-2.4)$ \\
\hline & Not Knowledgeable & 1 & 1 \\
\hline \multirow[t]{2}{*}{ During Post Natal } & Knowledgeable & $2.5(1.8-3.4) *$ & $1.1(0.7-1.7)$ \\
\hline & Not Knowledgeable & 1 & 1 \\
\hline \multirow[t]{2}{*}{ Previous delivery } & Yes & $0.7(0.5-1.0)$ & $0.4(0.1-2.3)$ \\
\hline & No & 1 & 1 \\
\hline
\end{tabular}

\section{DISCUSSION}

The practice of birth preparedness and complication reediness in this study was $42.3 \%$, which shows low proportion of the respondents' preparedness for birth and its complications. This points out that high proportion of the pregnant women did not receive the crucial strategy that highly reduces maternal and infant mortality and morbidity by enhancing preparedness for birth and its complication.

The finding of this study is lower than the study done in India which was $47.8 \%$ (5) and Dire Dawa at Dilchora Referral Hospital that was $54.7 \%$ (13). The difference of this finding with the study in India might be due to the deference in

DOI: http://dx.doi.org/10.4314/ejhs.v29i5.6 
facility, access to information and life style of the people among the countries. The difference with the study in Dire Dawa is due to the fact that the former study was done at hospital in which most of the respondents might have been from the urban and inhabitants near to the town. Therefore, it is known that the respondents from the town and around the town get information about the $\mathrm{BP} / \mathrm{CR}$ to seek for healthcare.

On the other hand, the finding of this study was higher than the study conducted in Ethiopia; Gurage zone Abeshige district, which was 37.2\% (14), Goba woreda which was 29.9\%(10) and Jimma Zone 29.4\% (11). The difference might be due to the time, the former studies were conducted before years. Therefore, it is obvious that the current quality of healthcare and availability of information about the $\mathrm{BP} / \mathrm{CR}$ is not the same as the previous years.

In this study, the most commonly practiced elements of $\mathrm{BP} / \mathrm{CR}$ were identification of place of delivery $(83.7 \%)$, identifying skilled birth attendants $(67.4 \%)$. And also $56.9 \%$ of respondents identified and prepared needed items for birth, $56.9 \%$ were ready by identifying danger signs and $45.2 \%$ saved money. It is nearly similar to the study conducted in India which indicated that $69.6 \%$ of the mothers identified a trained birth attendant for delivery, $63.8 \%$ of the mothers identified a health facility, $76.9 \%$ saved some money (5). A study in Ethiopia, Gurage Zone, showed that $95.1 \%$ of women made decision on place of delivery, $65.9 \%$ saved money, $50.1 \%$ identified skilled birth attendants (14). In Dire Dawa, 98.0\% respondents reported having identified their place of delivery, $75.7 \%$ identified their skilled birth attendant, 63.9\%) saved money (15). However, $17 \%$ planned to identify mode of transport, $13.4 \%$ decision maker and support person, and $5.6 \%$ planned to prepare blood donor which was still very low. These low levels of preparations were also stated in other previous studies in the country. The study conducted in Arsi Zone, Robe Woreda showed that 28.5\% identified a mode of transportation (16), and in Ahmara Reginal State in Basoliben District, 7\% arranged blood donors (17). In this study, being urban resident increases the likelihood of birth preparation and its complication readiness practice by two times. This finding is similar with previous studies in Ethiopia $(10,11)$.

This might be justified by the fact that women in urban areas had access to health information through different media, contact with health professionals working in health centers and hospitals. Relatively low barriers to health information due to distance and lack of transportations as compared to the rural women.

The women who are employed in the governmental organization and none government organization were increased the likelihood of preparation for birth and its complication by three times as compared to house wife women. Even though there is no literature support our findings. The reasons could be, that mothers employed in the governmental and none government organization were educated mothers, and also in most cases, live in the urban area. Being educated and living in urban areas increase the understanding of obstetric complications and chance access health information regarding $\mathrm{BP} / \mathrm{CR}$, which enables them to be prepared for birth and its complications.

In this study, having knowledge of BP/CR and knowledge of danger signs during pregnancy were more likely practice BP and CR by 13 and 2 times respectively. This findings are consistent with previous studies in the country (11-17). The implication of this finding could be when women become knowledgeable about birth preparedness and its complications, and danger sign during pregnancy, they are likely to practice the components of birth preparedness and also they can be ready to act upon it when any pregnancy, labour and child birth complications occur. However in this study, knowledge of danger signs during labour and child birth, and post-partum did not have statistically significant associations with $\mathrm{BP} / \mathrm{CR}$.

As strength, this study was conducted in the community as a zone with sufficient sample size. On the other hand, this study may have its own limitation because of its cross-sectional nature to ascertain temporal relationship. In addition, dichotomizing $\mathrm{BP} / \mathrm{CR}$ component and dander sign components may have its own limitations in identifying cut-off points. Possible efforts were 
made to use standard and as many variables as possible to make them objective.

The finding of this study revealed that the level of knowledge of key danger signs and the status of birth preparedness and complication readiness were still found to be low. Place of residence, occupation (governmental and nongovernmental organization), having knowledge about BP and CR and having knowledge about danger sign during pregnancy were the factors associated with birth preparedness and complication readiness.

\section{ACKNOWLEDGMENTS}

We would like to express our deepest gratitude to our data collectors, supervisors, zonal health department, woreda health office and study participants for their valuable contribution in the realization of this study. And also we would like to thank Mizan-Tepi University for your budget grant.

\section{REFERENCES}

1. JHPIEGO Maternal and Neonatal health $(\mathrm{MNH})$ Program. Birth preparedness and complication readiness: A matrix of shared responsibilities. JHPIEGO-MNH. 2001;23-31.

2. David Pu , Andrea B P And Fatuma M. Birth preparedness and complication readiness among women in Mpwapwa district, Tanzania; Tanzania Journal of Health Research, January 2012,14 (1).

3. World Health Organization. Department of Making Pregnancy Safer. WHO, Geneva, Switzerland. 2009.

4. Maternal and Neonatal Health (MNH) Program. Birth Preparedness Matrix, English, 2001.http://reprolineplus.org/system/files/resources /bpcr_matrix.

5. Agarwal S, Sethi V, Srivastava K, Jha PK, Baqui AH. Birth Preparedness and Complication Readiness among Slum Women in Indore City, India. J Health PopulNutr, 2010, 28(4): 383-391.

6. Mona Moore. A behavior change's approach to investigating factors influencing women's use of skilled care in Homa Bay District Kenya. The CHANGE project, Academy for Educational Development Group, Washington, D.C. December 2002.
7. Victora $M$ and Rubens CE. Global report on preterm birth and stillbirth. BMC Pregnancy and Childbirth 2010;10(Suppl1):S4 http://www.biomedcentral.com/14712393/10/S1/S4

8. CSA [Ethiopia] and ICF International. Ethiopia demographic and health survey report 2016. Addis Ababa, Ethiopia and Calverton, Maryland, USA: Central Statistical Agency and ICF International; 2016.

9. Bench Maji zonal health departments. Annual report of zonal health desk of Bench Maji zone, Mizan, Ethiopia, 2016.

10. Desalegn M and Daniel B. Birth preparedness and complication readiness among women of child bearing age group in Gobaworeda, Oromia region, Ethiopia. BMC Pregnancy and Childbirth 2014; $14: 282$

11. Gurmesa T D, Mesganaw FA, Alemayehu W. Factors affecting birth preparedness and complication readiness in Jimma Zone, Southwest Ethiopia: a multilevel analysis. Pan African Medical Journm. 2014; 19:272.

12. JHPIEGO. Monitoring Birth Preparedness and complication readiness tools and indicators for maternal and newborn health. JHPIEGO, 2004.

13. Musa A, Amano A. Determinants of Birth Preparedness and Complication Readiness Among Pregnant Woman Attending Antenatal Care at Dilchora Referral Hospital, Dire Dawa City, East Ethiopia. GynecolObstet (Sunnyvale), 2016;6:356.

14. Zebre K and Kaba M. Birth Preparedness and Complication Readiness Among Rural Women Of Reproductive Age in Abeshige District, Gurage Zone, SNNPR, Ethiopia, International Journals of Women's Health, 2015;9:11-12.

15. Sena BK and Bosena T. Predictors of Birth Preparedness and Complication Readiness among Pregnant Women in Jimma Town, South West Ethiopia, a Cross Sectional Study; Research 2014; 1:595.

16. Kaso and Addisse. Birth preparedness and complication readiness in Robe Woreda, Arsi Zone, and Oromia Region, Central Ethiopia: a cross-sectional study. Reproductive Health 2014; 11:55.

17. Bishaw W Awoke W, Teshome M. Birth Preparedness and Complication Readiness and Associated Factors among Pregnant Women in Basoliben District, Amhara Regional State, Northwest Ethiopia. Primary Health Care, 2013;4:171 